\title{
The Effect of Education on Agricultura Productivity: Implication for Rural Development
}

\author{
Salisu Ahmed Kabiru \\ Public Administration Department

\section{Rozita Arshad} \\ School of Government, University Utara Malaysia
}

Faculty of Social and Management Sciences Umaru Musa Yar'adua University Katsina

\begin{abstract}
Agriculture provide 60 percent of the world population with food for survival and play a vital role to the economic and social development of low-income countries. The purpose of this study was to examine the effects of education on agricultural productivity in Katsina State Nigeria. The study adopted survey approach and 434 questionnaires was distributed to the selected respondents from 6 local government areas of Katsina State. A total of 400 useable questionnaire was returned accounting for 92 percent rate of returned, which was utilized for analyzing the data using PLS statistical tool. The main findings of the analysis revealed that, education has a significant effect on agricultural productivity.
\end{abstract}

Key words: Education, Agricultural Productivity, Rural development.

\section{Introduction}

The issue of agricultural productivity in the world is so paramount, and topical that it has occupied a front burner in food security discourse as well as in development discourse. According to Food and Agricultural Organization (FAO), agriculture provide 60 percent of the world population with food for survival and play a vital role to the economic and social development of low-income countries (FAO, 2018).

A Sustain food provision for 90 percent of the world population who are not farmers need a viable mechanism that will facilitate high agricultural productivity. The importance of agriculture to the life of any economy cannot be over-emphasis, as it is the backbone of our economic system. Apart, from the provision of food and other vital raw material for the industries, agriculture provides employment opportunities to a significant number of people in both rural and urban areas of a country.

For decades, agriculture had been synonymous with the production of basic food crops, but recent trends had reinvigorate agriculture and allied it with other occupations to be recognize as part of agriculture such as forestry, fruit cultivation, dairy, poultry, mushroom, and bee 
keeping, as well as marketing, processing, and distribution of agricultural products are all accepted as a part of modern agriculture.

Education had been identified as most viable mechanism for enhancing agricultural productivity as shown by some studies. For example, in a study by Das (2012), it was found that an additional one year of schooling increases agricultural output. Similarly, in another study by Bandiera and Rasul, (2006), it was found that literate farmers, with secondary school education, were 26 percent more likely to venture into cash crop farming, than those with primary school education.

However, despite the importance role play by education in enhancing agricultural productivity, little effort has been paid to enhance the knowledge base of farmers, especially those from the rural areas where more than 70 percent of the people rely on agriculture for their livelihood. This paper, therefore, examine the effect of education on agricultural productivity, the paper uses empirical approach as such the data was generated through questionnaire and PLS was used as tool for data analysis.

\section{Literature Review}

Ferreira (2015) examined the relationship between education and agricultural productivity in Malawi and the result of the analysis reveals a positive significant relationship between education and agricultural productivity, especially in maize production, and all other product. This result is consistent with the findings of Afari (2001) in Ghana, where educational attainment of the maize farmers has positive effect on the productivite level of maize production.

In a similar study, Yasmeen (2011) examined the impact of education on farmer's agricultural productivity. The result from the analysis reveals a positive significant relationship between education and agricultural productivity in all agricultural product. This result is also consistent with findings from Ferreira (2015) in Malawi, where it was found that, literate farmers tends to use new farming techniques and fertilizers than the illiterate ones.

Similar, Djomo (2012) examined the effect of human capital on agricultural productivity in Cameroon focus on the impact of human educational attainment on agricultural productivity. The result from the analysis reveals that, additional year of experience and schooling increases agricultural productivity. The study further found that, an additional year of experience reduces the level of inefficiency, and additional one year of education reduces the level of inefficiency. Furthermore, the study found that, an additional year of schooling and experience increase farmer's income.

Similar, Ndour (2017) examined the effect of human capital on agricultural productivity in Senegal. The study revealed a significant relationship between human capital and technical efficiency. In the same vein, Fielke (2014) examined the importance of farmer's education in relation to agricultural productivity in Australia. The study found that, education in general contributes to higher thinking regarding the social and environmental outcomes of individual agri-businesses actions.

In the same vein, a study conducted by Klasen (2011) found that, education increases earning of farmers, which in turn, improves their well-being significantly. In another study by Tersoo (2014), it was found that farmers with numerical ability tends to interpret and respond to new information pertaining to new discovery in the field of farming, and that education has the capacity to improve the farmers productivity level through the use of modern technology, which could assist them in overcoming poverty. 
Similarly, in Nepal, studies have found that, farmers that had obtained a complete primary education qualification were likely to adopt to soil conservation techniques by 26 percent, and they are likely to be more conscious of taking proactive measures in preventing erosion than those with no education (Admassie, 2008).

Based on the analysis of the research findings above, in which it was found that, there exists a relationship between education and agricultural productivity, this study postulates the that says:

H1: There is significance relationship between Education and agricultural productivity

\section{Methodology}

This study adopted survey method, and the data for the study was obtained through questionnaire which were distributed to 434 respondents selected from six local government areas in Katsina State using Multi-stage sampling techniques. A total of 400 useable questionnaires were returned accounting for 92 percent rate of retuned, and PLS statistics was used as a tool for data analysis.

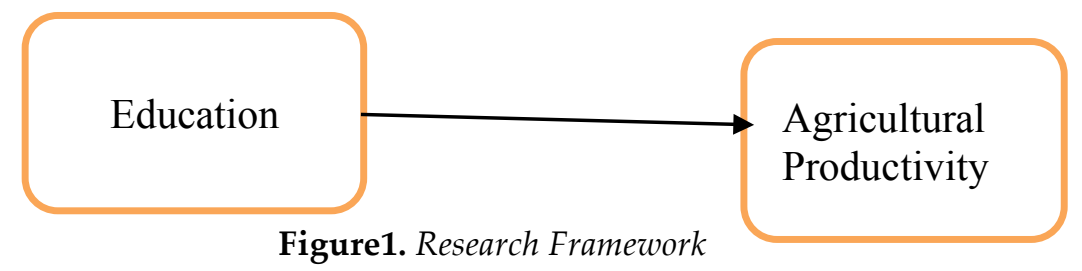

\section{Data Analysis}

The statistical tool adopted for this study is PLS-SEM as it's one of the most widely used tool for analysis in social and behavioral sciences disciplines. The PLS-SEM is among the most recently found accurate tools in analyzing relationship between and among complicated variables. Additionally, PLS exhibit strong statistical accuracy and reliability than other statistical tool having the power to run multiple regression analysis simultaneously (Tabri, 2012).

\section{Result and Discussion}

The result and discussion of the analysis of the relationship between the construct of this study will be in two segments, the first part will discuss the result of the measurement model analysis which deals with reliability and validity of the instrument, while the second part, will discuss the result of the analysis of the structural model which deals with testing of the hypothesis.

\section{Measurement outer model}

The assessment of the measurement model was done in steps, in the first step, the internal consistency of the items was determined where each item indicate a significance contribution in measuring the variable or construct, and in the second step, the measurement model was verified through construct reliability test (composite reliability, convergent validity, and Cronbach Alpha). In order to meet the requirement for reliability and validity criteria, it is essential in quantitative research to carry out construct reliability test (Hair, 2014).

\section{Measurement validity}

For this study to meet the measurement validity requirement, convergent validity was carry out by assessing the loadings, average variance extracted (AVE) and composite reliability (CR) as well. As indicated in table 2, the loadings were all above the standard value of 0.4 (Hair, 2014). The CR, CA, and rho- were all greater than 0.6, similarly, the AVE value was greater than the threshold of 0.5 (Hair, 2014). 
Table 1: Reliability Test

\begin{tabular}{|c|c|c|c|c|c|c|}
\hline Construct & Items & Loadings & $\mathrm{CA}$ & Rho & CR & AVE \\
\hline EDUCATION & & & 0.952 & 0.958 & 0.959 & 0.700 \\
\hline EI & & 0.779 & & & & \\
\hline E2 & & 0.865 & & & & \\
\hline E3 & & 0.876 & & & & \\
\hline E4 & & 0.847 & & & & \\
\hline E5 & & 0.859 & & & & \\
\hline E6 & & 0.823 & & & & \\
\hline E7 & & 0.828 & & & & \\
\hline E8 & & 0.864 & & & & \\
\hline E9 & & 0.867 & & & & \\
\hline E10 & & 0.746 & & & & \\
\hline AGRIC & & & 0.957 & 0.961 & 0.963 & 0.703 \\
\hline AG1 & & 0.860 & & & & \\
\hline AG2 & & 0.834 & & & & \\
\hline AG3 & & 0.801 & & & & \\
\hline AG4 & & 0.842 & & & & \\
\hline AG5 & & 0.815 & & & & \\
\hline AG6 & & 0.842 & & & & \\
\hline AG7 & & 0.801 & & & & \\
\hline AG8 & & 0.834 & & & & \\
\hline AG9 & & 0.863 & & & & \\
\hline AG10 & & 0.888 & & & & \\
\hline
\end{tabular}

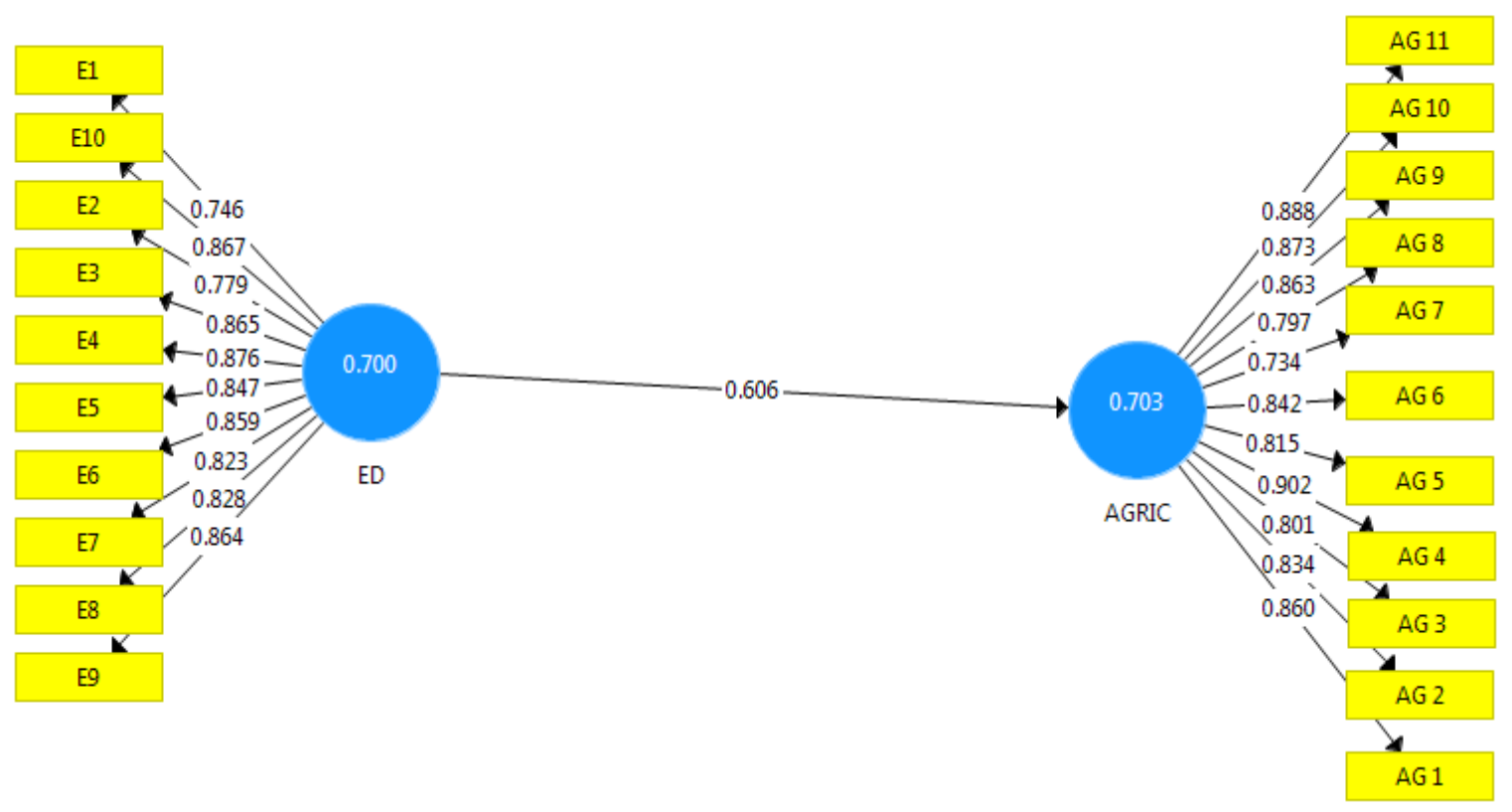

Figure 1: Measurement Model

As suggested by Fornell (1981), Loading and cross loading techniques was use by this study to assess the discriminant validity of the construct using AVE-SE, and Hererotrait (HTMT) matric. Table 3 indicates that, the constructs have achieved the discriminant validity test as the diagonal values of the construct were greater than the horizontal and vertical values. 
Table 3: Fornnell Larker Discriminant Validity Criteria

\begin{tabular}{lll}
\hline Construct & $\mathbf{1}$ & $\mathbf{2}$ \\
\hline Education & 0.646 & \\
& 0.404 & \\
Agric & & 0.406 \\
\hline
\end{tabular}

In order to assess the item level, discriminant validity was utilized using cross loadings, and for discriminant validity to be achieved, the loading of the items in each construct must be greater than its loadings (Sekaran, 2016). As for this study, the discriminant validity has been achieved as each item in the loading (bold) were greater than its cross-loading as indicated in table 4.

Table 4: Loading and Cross Loading

\begin{tabular}{llll}
\hline Construct & Items & EDUCATION & AGRICULTURE \\
\hline EDUCATION & & & \\
& EI & 0.746 & \\
& E2 & 0.779 & \\
E3 & 0.865 & \\
& E4 & 0.876 & \\
& E5 & 0.847 & \\
& E6 & 0.859 & \\
& E7 & 0.823 & \\
EG8 & 0.828 & \\
& E9 & 0.864 & 0.860 \\
& E10 & 0.867 & 0.834 \\
& & 0.801 \\
& AG1 & & 0.842 \\
& AG2 & & 0.815 \\
& AG3 & & 0.842 \\
& AG4 & & 0.801 \\
& AG5 & & 0.834 \\
& AG6 & & 0.863 \\
& AG7 & & 0.888 \\
& AG8 & & 0.873 \\
\hline
\end{tabular}

This study assessed HTMT by adopting a threshold of 0.85 as suggested by Tabri and Elliott (2012), and any value less than the adopted value indicates discriminant validity. As shown in table 2, this study has achieved discriminant validity as the highest value in the matrix is 0.461 which is less than the adopted threshold of 0.85 .

\section{Testing of Hypothesis}

This study determined the direct relationship between education and agricultural productivity using bootstrapping and the result of the analysis indicates that, there exist positive relationship between the two variables as these; $\mathrm{B}=0.606, \mathrm{SE}=0.048, \mathrm{TV}=12.692, \mathrm{P}=0.000$, therefore, the 
hypothesis which says there is significant relationship between education and agricultural productivity was supported. The result of this analysis was indicated in table 5 and figure 2 respectively.

Table 5: Result of the Structural Model Assessment (Hypothesis Testing).

\begin{tabular}{llllll}
\hline Relationship & B & Std & $\mathbf{T}$ & $\mathbf{P}<$ & Decision \\
\hline Edu>Agric & 0.606 & 0.048 & 12.692 & 0.000 & Significance \\
\hline
\end{tabular}

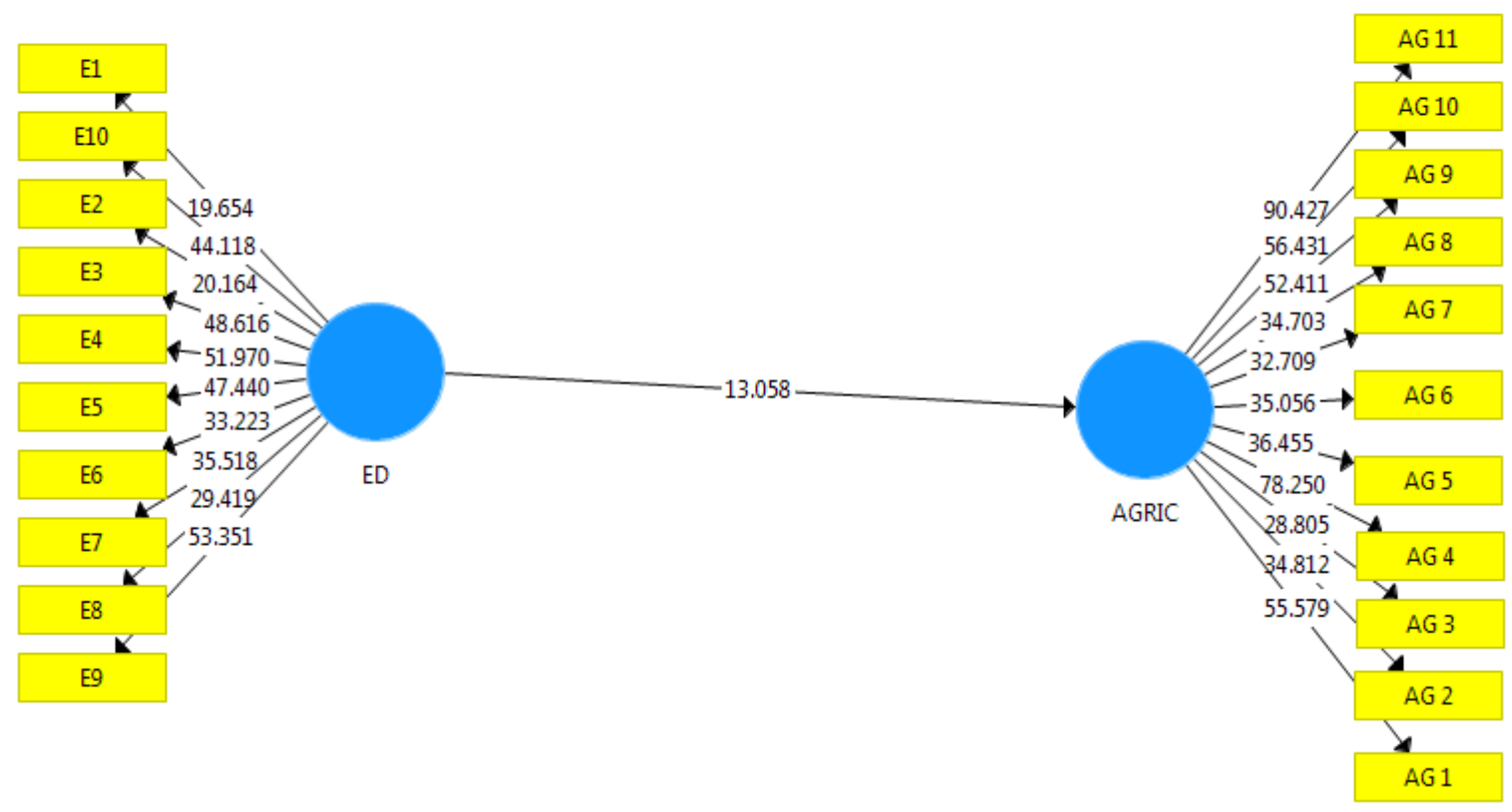

Figure 2: Structural Model Assessment (Direct Effect)

\section{Discussion, Implication, Limitation, and Future Research}

Using the PLS statistical tool, this study, has investigated the direct relationship between education and agricultural productivity. Firstly, the reliability and validity of the instruments were determined through measurement model analysis as indicated in figure 1, which indicated that, the instrument have met the criteria for further analysis. Secondly, the relationship between education and agricultural productivity was analyzed through bootstrapping, and the result indicated a significant relationship as shown in table 5 and figure 2 respectively.

This result has provided yet another evidence that, education is an enhancer of agricultural productivity and it's also a leeway out of poverty as it enhances agricultural output. The findings from this study, have contributed to the advancement of knowledge for being conducted in African context, while the construct of this study, and their relationship were majorly investigated in Western and Asian context. Additionally, investigating the construct in a different context which is Katsina State Nigeria is another uniqueness of this study.

\section{Implication of the Result}

One of the major explicit implication for policy maker on agricultural productivity and rural development by extension, as drawn from this study was that, education has a significant 
influence on agricultural productivity. This implies that, the more people are educated the higher the agricultural productivity, this also means that, education could serve as mechanism for rural development and poverty reduction as well.

\section{Conclusion}

Conclusively, this study examined the effect of education on agricultural productivity. The result from the analysis shows that, education has a significant influence on agricultural productivity which implies that, the more education is provided in the areas, the higher the agricultural productivity in Katsina State Nigeria. From the findings of this study, it has been proved that, to facilitate and realized rural development objective, government should provide more schools in the rural areas in order to boost agricultural productivity and by extension achieved rural development.

\section{References}

Admassie, A., Adenew, B., \& Tadege, A. (2008). Perceptions of stakeholders on climate change and adaptation strategies in Ethiopia. International Food Policy Research Institute. Retrived

from https://scholar.google.com/scholar?hl=en\&as_sdt=0\%2C5\&q=Admassie\%2C+A.+\%282008 \%29\&btnG=\#d=gs_cit\&u=\%2Fscholar\%3Fq\%3Dinfo\%3Agi6zdHCJ7UJ\%3Ascholar.google. com\%2F\%26output\%3Dcite\%26scirp\%3D0\%26hl\%3Den (accessed 20th May, 2019)

Afari, E. (2001). The effect of farmers'education on farm productivity and income in ghana: implication for food security (Doctoral dissertation, University of Ghana).

Bandiera. Rasul, I.(2006). Social network and technology adoption in northern Mozambique. The Economic Journal 116(514), 869-902.

Djomo, J. M. N., \& Sikod, F. (2012). The effects of human capital on agricultural productivity and farmer's income in Cameroon. International Business Research, 5(4), 149.

FAO (2018). The State of food ecurity and Nnutrition in the World 2018. Retrieved from https://www.google.com/search?ei=xX6sXJmlOvqZ1fAP2vyP0Ac\&q=fao+report+on+food +security+2018\&oq=fao+report+\&gs_l=psyab.1.0.0110.11032.14195..20516...0.0..0.603.2474.0 j3j2j1j1j101gws-wiz0i71j0i131i67j0i67.CCRZf_x7H1o (accessed 20th May, 2019)

Ferreira, T.(2015) Does education enhance productivity in smallholder agriculture? causal evidence from Malawi. Retrieved from https://scholar.google.com/scholar?hl=en\&as_sdt=0\%2C5\&q=Ferreira\%2C+T.\%282015\%29 ++Does+education+enhance+productivity+in+smallholder+agriculture $\% 3 \mathrm{~F}+$ causal+eviden ce+from + Malawi. $+\& b$ tnG $=($ accessed 1th February 2019)

Fielke, S. J., \& Bardsley, D. K. (2014). The importance of farmer education in South Australia. Land Use Policy, 39, 301-312.

Fornell, C., \& Larcker, D. F. (1981). Evaluating structural equation models with unobservable variables and measurement error. Journal of Marketing Research, 39-50.

Hair, F, J., Sarstedt, M., Hopkins, L., \& G. Kuppelwieser, V. (2014). Partial least squares structural equation modeling (PLS-SEM) An emerging tool in business research. European Business Review, 26(2), 106-121.

Klasen, S., \& Schüler, D. (2011). Reforming the gender-related development index and the gender empowerment measure: Implementing some specific proposals. Feminist Economics, 17(1), 1-30. 
Ndour, C. T. (2017). Effects of human capital on agricultural productivity in Senegal. World Scientific News, (64), 34-43.

Sekaran,U., Bougie, R.(2016).Research method for business: A skill building approach, UK: John Wiley \& Son

Stampini, M., \& Davis, B. (2006). Discerning transient from chronic poverty in Nicaragua: measurement with a two-period panel data set. The European Journal of Development Research, 18(1), 105-130.

Tabri, N., \& Elliott, C. M. (2012). Principles and practice of structural equation modeling. Canadian Graduate Journal of Sociology and Criminology, 1(1), 59-60.

Tersoo, P. (2014). Agribusiness as a veritable tool for rural development in Nigeria. International Letters of Social and Humanities Science, 14, (7), 26-36

Yasmeen, K., Abbasian, E., \& Hussain, T. (2011). 'Impact of educated farmer on Agricultural Product. Journal of Public Administration and Governance, 1(2), 158-164. 